Originalveröffentlichung in: Edgar Wolfrum, Täterbilder. Die Konstruktion der NS-Täter durch die deutsche Nachkriegsjustiz, in: Hans Braun/Uta Gerhardt/Everhardt Holtmann (Hg.), Die lange Stunde Null. Nomos, Baden-Baden 2007, S. 119-139.

\title{
Täterbilder
}

\section{Die Konstruktion der NS-Täter durch die deutsche Nachkriegsjustiz}

\author{
Edgar Wolfrum
}

\section{Einleitung \\ Das erkenntnistheoretische »Feld« der Täterbilder}

Das »past-beating«, das Vergangenheitsbewältigen, ist zu einer weltweiten Industrie in Gesellschaften geworden, die den Weg von einer Diktatur zur Demokratie zurücklegen. Es gibt acht Ziele und neun Wege der Vergangenheitsbewältigung. Die Ziele können sein: 1. Wahrheit, 2. Gerechtigkeit, 3. Anerkennung von Verantwortung und Schuld, 4. Verhinderung erneuter Menschenrechtsverletzungen, 5. Konsolidierung demokratischer Verhältnisse, 6. Heilung, verstanden im psychologischen, individuellen Sinn, 7. Reinigung, also eine gesellschaftliche Katharsis, und 8. Versöhnung. $\mathrm{Zu}$ diesen Zielen können neun Wege führen: 1. Säuberungen, wie etwa Entnazifizierung, 2. Wahrheitskommissionen, 3. Öffnung der Archive, 4. Kriminalisierung der Leugnung von Verbrechen, 5. Gedenk- und Erinnerungsarbeit in Museen und Gedenkstätten, 6. Symbolische Versöhnungsakte, 7. Entschädigungen und Reparationen, 8. Behebung struktureller Missstände, die aus der überwundenen Diktatur herrühren - und schließlich, was ganz am Anfang hätte stehen müssen, aber für den Schluss aufgespart wurde: 9. Gerichtsverfahren.

Die strafrechtliche Verfolgung von NS-Verbrechen ist bis heute nicht abgeschlossen. Noch immer laufen eine Reihe von Ermittlungsverfahren gegen mutmaßliche NS-Täter. In der Zentralen Stelle der Landesjustizverwaltungen zur Aufklärung nationalsozialistischer Gewaltverbrechen in Ludwigsburg waren zu Beginn des Jahres 2001 noch knapp 20 Vorermittlungsverfahren anhängig. Bis Ende 1998 wurden durch die westdeutsche Justiz Ermittlungs- und Vorermittlungsverfahren gegen 106.496 Personen eingeleitet. Unter diesen wurden indessen lediglich 6.495 rechtskräftig verurteilt - was einem Anteil von 6,4 \% entsprach. ${ }^{1}$ Besonders auffällig ist, dass trotz Täterschaft überwiegend wegen Beihilfe verurteilt wurde, also die Täter vorwiegend als Gehilfen eingestuft wurden. Man könnte überspitzt formulieren: »Ein Täter, nämlich Hitler, und 60 Millionen Gehilfen«. Wie ist diese Strafverfolgungsbilanz zu werten? War sie ein Erfolg, wie man in den 60er Jahren glaubte? Oder war sie, was Bundesjustizminister Schmidt-Jorzig (FDP) 1996 meinte: Kein

1 Michael Greve, Der justitielle und rechtspolitische Umgang mit den NS-Gewaltverbrechen in den sechziger Jahren, Frankfurt a. M. 2001, S. 11. 
Ruhmesblatt für die bundesdeutsche Justiz? ${ }^{2}$ Man muss sich fragen: Wo sind die Gründe für die offensichtlichen Defizite zu suchen? Fehlten denn der Wille oder die Bereitschaft in der Bundesrepublik, Nazi-Verbrechen gründlich zu verfolgen?

Jedenfalls lässt sich anhand der Prozessstatistik festhalten: Die nach dem Untergang des »Dritten Reiches« offenkundige Bereitschaft zu einer schonungslosen Aufdeckung, Verfolgung und Bestrafung der NS-Verbrechen (durch alliierte Verfahren, insbesondere den Prozess gegen die Hauptkriegsverbrecher in Nürnberg, und auch durch deutsche Gerichte ${ }^{3}$ ) flaute zu Beginn der 50er Jahre ab. Dadurch entstand der Eindruck, dass sich die bundesdeutschen Strafverfolgungsbehörden am Rande einer »Justizverweigerung « bewegten. Stichworte müssen hier genügen: Für die fünfziger Jahre stehen vor allem Straffreiheitsgesetze, Reintegration von Tätern sowie von der Politik demonstrierte Solidarität mit den von der Nürnberger »Siegerjustiz« verurteilten »Kriegsverbrechern «. ${ }^{4}$ Das änderte sich mit der Einrichtung der Zentralen Stelle 1958..$^{5}$ In den fünfziger Jahren galten andere Rahmenbedingungen als unmittelbar nach Kriegsende: der Kalte Krieg, der Korea-Krieg und die Wiederbewaffnung warfen auch einen Schatten auf die strafrechtliche Ahndung der NSVerbrechen. Die Strafverfolgung der NS-Verbrechen vollzog sich jedenfalls in einem tendenziell auf Verdrängung und Schuldabwehr ausgerichteten gesellschaftlichen Klima, wo oft die Solidarität mit den Tätern stärker ausgeprägt war als die mit den Opfern. Aber in den folgenden Jahrzehnten änderte sich die Bereitschaft, NSTäter gerichtlich zu verfolgen, entscheidend.

Die Zeitgeschichtsschreibung hat sich dem Forschungsgegenstand der strafrechtlichen Aufarbeitung der NS-Verbrechen bislang weitgehend verschlossen. ${ }^{6}$ Verantwortlich dafür sind die Probleme für den Historiker, sich in die juristische Sichtweise hineinzuversetzen und die Rechtsfiguren nachzuvollziehen, so etwa im deutschen Strafrecht: Die Unterscheidung der Beteiligungsformen Täterschaft bzw. Mittäterschaft ist entscheidend, und die beiden Teilnahmeformen der Anstiftung und Beihilfe sind zentral - was für Historiker aufgeschlüsselt werden muss. ${ }^{7}$ Allgemein gesagt

2 Vgl. ibid., S. 13. Siehe auch Joachim Perels, Der Mythos von der Vergangenheitsbewältigung, Die Zeit, Nr. 5, 6.1.2006.

3 Dazu siehe den Beitrag von Edith Raim, Der Wiederaufbau der westdeutschen Justiz unter alliierter Aufsicht und die Verfolgung von NS-Verbrechen 1945 bis 1949/1950, in diesem Band.

4 Norbert Frei, Vergangenheitspolitik. Die Anfänge der Bundesrepublik und die NS-Vergangenheit, München 1996, S. 133 ff.

5 Rüdiger Fleiter, Die Ludwigsburger Zentrale Stelle und ihr politisches und gesellschaftliches Umfeld, Geschichte in Wissenschaft und Unterricht (GWU), 53, 2002, S. 32-50.

6 Die vorliegenden Thesen und ersten Ergebnisse basieren auf einem Forschungsprojekt, das im Bereich der Zeitgeschichte am Historischen Seminar der Universität Heidelberg von der Volkswagen Stiftung gefördert wird: »Das Bild der Holocaust-Täter in der deutschen Rechtsprechung«.

7 In letzter Zeit ist ein Aufschwung in der Forschung zu verzeichnen; vgl. Thomas Horstmann und Heike Litzinger, An den Grenzen des Rechts. Gespräche mit Juristen über die Verfolgung von NS-Verbrechern, Wissenschaftliche Reihe des Fritz Bauer Instituts, Bd. 14, Frankfurt a. M. und New York 2006; Stefan Hördler, Aspekte der Täterforschung. Eine kritische Bilanz, in: 
sind mit der Ahndung durch Gerichtsverfahren große Probleme verbunden: ${ }^{8}$ Denn der Modus der Gerichtsverhandlung begünstigt eine Personalisierung des Nationalsozialismus, weshalb Fritz Bauer, der für den Auschwitz-Prozess maßgebliche Generalstaatsanwalt, von der »Atomisierung und Parzellierung« des kollektiven Geschehens sprach, das durch die Strafverfolgung unvermeidlich »entschärft« und »privatisiert« worden sei. ${ }^{9}$

Als Fragestellungen erscheinen Schnittpunkte zwischen Zeitgeschichte und Justiz sinnvoll, die die Entwicklungen und Veränderungen der Täterbilder in den letzten sechzig Jahren verdeutlichen. Ich möchte einige nennen: Welche Täterkonstruktionen scheinen auf, d.h. welche Täterbilder werden durch die Justiz und Rechtsprechung entworfen? Wie bestimmen juristische Denk- und Argumentationsfiguren die Urteils- und Strafzumessung der Gerichte (Befehlsnotstand, Nötigungszustand, Pflichtenkollision, Verbotsirrtum der Täter, übergesetzlicher Notstand, übergesetzlicher Schuldausschließungsgrund)? Hat die Rechtsprechung der Bundesrepublik zur moralischen Exkulpation der Nachkriegsgesellschaft beigetragen?

Durch eine Inhaltsanalyse exemplarischer Urteile und die Einbettung der Rechtsprechung in den gesellschaftlichen Kontext kann man Antworten auf diese Problemstellungen finden. Darin werden auch die Fragen berührt: Lassen sich Wandlungen im Zeitverlauf feststellen? Veränderte sich das Strafmaß im Laufe der Jahre? Gibt es internationale und interregionale Unterschiede? Was heißt Konstruktion von Täter- und Geschichtsbildern? In welchem Zusammenhang stehen der öffentliche Diskurs, die juristische Konstruktion und die populäre Vermittlung von Täterbildern? Wie beeinflussen sie sich gegenseitig?

In diesem thematischen Rahmen kann man ein erkenntnistheoretisches »Feld « abstecken. Es ergibt sich aus 1. der Vergangenheitspolitik, also den exekutiven, legislativen und justiziellen Maßnahmen, und 2. der Geschichtspolitik, also den Diskur-

Petra Frank und Stefan Hördler (Hg.), Der Nationalsozialismus im Spiegel des öffentlichen Gedächtnisses. Formen der Aufarbeitung und des Gedenkens, Berlin 2005, S. 23-45; Anne Klein und Jürgen Wilhelm (Hg.), NS-Unrecht vor Kölner Gerichten, Köln 2003; Kerstin Freudiger, Die juristische Aufarbeitung von NS-Verbrechen, Tübingen 2002; Friedrich Hoffmann, Die Verfolgung der nationalsozialistischen Gewaltverbrechen in Hessen, Baden-Baden 2001.

8 Besonders zu beachten sind die beiden beispielhaften Studien von Marc von Miquel, Ahnden oder amnestieren? Westdeutsche Justiz und Vergangenheitspolitik in den sechziger Jahren, Beiträge zur Geschichte des 20. Jahrhunderts, Bd. 1, Göttingen 2004 und Claudia Moisel, Frankreich und die deutschen Kriegsverbrecher. Politik und Praxis der Strafverfolgung nach dem Zweiten Weltkrieg, Beiträge zur Geschichte des 20. Jahrhunderts, Bd. 2, Göttingen 2004. Der neueste Literaturbericht ist von Christoph Nonn, Nationalsozialismus als Geschichte. Neuere Literatur zum Umgang mit der NS-Vergangenheit in Deutschland, Newe Politische Literatur (NPL), 49, 2005, S. 407-426.

9 Vgl. Claudia Fröhlich, Fritz Bauer - Ungehorsam und Widerstand sind ein »wichtiger Teil unserer Neubesinnung auf die demokratischen Grundwerte«, in: Claudia Fröhlich und Michael Kohlstruck (Hg.), Engagierte Demokraten. Vergangenheitspolitik in kritischer Absicht, Münster 1999, S. 106-120. 
sen über Geschichte in der Öffentlichkeit. ${ }^{10}$ In diesem »Feld « muss man die juristischen Prinzipien der Konstruktion von Tätern, die strafrechtlichen Denkfiguren und die Argumentationskonfigurationen der Urteile näher betrachten. $\mathrm{Zu}$ beachten sind auch vorbewusste, außernormative Einstellungen und spezifische Menschenbilder bei Richtern, Staatsanwälten und Verteidigern. Die Frage, inwiefern die Rechtsprechung das öffentliche Täterbild mitbestimmt, ist wohl kaum abschließend zu beantworten. Man kann versuchen, durch die Lektüre und Interpretation von Strafprozessakten als Quellen, die an ein juristisches Relevanzsystem gebunden sind und zugleich Konstruktionen und Festschreibungen gesellschaftlicher Art enthalten, eine Antwort auf das Problem der Täterbilder zu geben.

Aufgabe eines Strafrichters in einem demokratischen Rechtsstaat ist, die empirischen Sachverhalte zu prüfen, die normativen, vom Gesetzgeber formulierten Tatbestände zugrunde zu legen und entsprechend die Schuld eines Angeklagten zu beurteilen. Dem Beschuldigten steht ohne Ansehung der Person das Recht zu, dass das Gericht seinen Fall individuell und unter Berücksichtigung von Wissen und Wollen zum Tathergang bzw. bei Verwirklichung der Tat abwägt. Stereotypisierungen widersprechen einem rechtsstaatlichen Verfahren. Man wird daher in Urteilstexten keine Stereotypen ausformuliert finden. Gleichzeitig aber leben Richter nicht außerhalb der Gesellschaft. In der Öffentlichkeit werden Annahmen über Verbrechen und Verbrecher von sehr vielen Menschen geteilt und entfalten eine weitreichende Wirkungsmacht. Dies betrifft sowohl Annahmen über eine Tat im Hinblick auf den sozialen Status des Täters - nämlich dass sich hohe oder niedrige gesellschaftliche Stellung unterschiedlich auswirken - als auch Annahmen über generations- oder geschlechterspezifische Typisierungen von Person oder Motiv eines Verbrechers. ${ }^{11}$

Verbrechen von Frauen rufen oft Bestürzung oder Unverständnis hervor, weil konventionelle Vorstellungen des vermeintlich friedfertigen und fürsorglichen weiblichen Wesens über den Haufen geworfen werden. An Frauen werden dabei höhere moralische Anforderungen gestellt, weshalb ihnen Gewalttätigkeit stärker anzulasten sei als Männern. Entsprechend wird ihnen Versagen hinsichtlich ihrer vermeintlich weiblichen »Bestimmung« vorgeworfen. Es liegt nahe, dass solche Ansichten auch die Vorverständnisse prägen, die unreflektiert in Gerichtsverfahren und Rechtsprechung einfließen. Für die Prozesse gegen deutsche Kriegs- und NS-Gewaltverbrecher nach 1945 gibt es zwar bislang keine rechtswissenschaftliche oder rechtshistorische Untersuchung, die diese Überlegung zu ihrem Ausgangpunkt nähme, aber man darf vermuten, dass hier ein Thema vorliegt, das im Zusammenhang der Täterbilder aufschlussreich ist.

10 Vgl. Edgar Wolfrum, Geschichtspolitik in der Bundesrepublik Deutschland. Der Weg zur bundesrepublikanischen Erinnerung 1948-1990, Darmstadt 1999; Heinrich August Winkler (Hg.), Griff nach der Deutungsmacht. Zur Geschichte der Geschichtspolitik in Deutschland, Göttingen 2004.

11 Vgl. Ulrike Weckel und Edgar Wolfrum (Hg.), »Bestien« und »Befehlsempfänger». Frauen und Männer in NS-Prozessen nach 1945, Göttingen 2003. 
Deshalb kommt neben der Vergangenheitspolitik die Geschichtspolitik in die Betrachtung mit hinein. Daraus ergeben sich die Fragen: Wie wirken öffentliche Diskurse wiederum auf die Rechtsprechung zurück? Welche Rolle spielt die historische Wissenschaft, welche Rolle haben neue wissenschaftliche Erkenntnisse und Gutachten für die NS-Prozesse? Vor diesem Hintergrund muss der deutsche Systemkonflikt, der bis 1989 herrschte, in der Rückschau berücksichtigt werden: ${ }^{12}$ Für Bonn stand nachweislich die juristische Ahndung der NS-Prozesse vielfach nicht um ihrer selbst willen im Zentrum, sondern oft genug ging es bei der Verfolgung von NSVerbrechen auch darum, die Bundesrepublik vor Propagandaangriffen aus dem Ostblock zu bewahren.

Anschaulich kann man formulieren: Der Richter, der Historiker und der Politiker haben unterschiedliche Wirkungskreise. Die »Wahrheit" des Richters ist formell, reduktionistisch, wird als Urteil unmittelbar folgenreich und ist rechtskräftig, was sie dauerhaft macht. Nichts davon trifft auf historische Erkenntnisse zu. Der Historiker sagt seine Meinung und geht von dannen. Seine Wahrheit ist steter Revision unterworfen. Diese Differenz wird noch offensichtlicher, wenn neben der Justiz und der Wissenschaft auch die Politik gewürdigt wird, die als eine dritte Instanz unmittelbar an der Verfolgung von NS-Verbrechen beteiligt ist.

Bekanntlich muss noch nach verschiedenen Tätergruppen unterschieden werden. Rüters Urteilssammlung kann für den Zeitraum bis $1965^{13}$ in acht Kategorien aufgeschlüsselt werden: Euthanasie, Schreibtischverbrechen, Vernichtungskrieg, Massenvernichtungsverbrechen durch Einsatzgruppen, Massenvernichtungsverbrechen in Lagern, Gewaltverbrechen in Lagern, richterliche Todesurteile sowie Denunziation. Diese acht Kategorien lassen sich vier Großverbrechen zuordnen: der Vernichtung des europäischen Judentums (Massenvernichtungsverbrechen in Lagern oder durch Einsatzgruppen, Schreibtischverbrechen), Euthanasie, Vernichtungskrieg (Kriegsverbrechen, Gewaltverbrechen in Lagern), Justizverbrechen (richterliche Todesurteile, Denunziationen).

\section{Nürnberger Prozesse: Normsetzung und Viktimisierungsfalle}

Der Nürnberger Prozess gegen 24 hochrangige nationalsozialistische Politiker und Militärs, die als Hauptkriegsverbrecher angeklagt wurden, markiert den Übergang in die Friedenszeit nach dem Zweiten Weltkrieg. Er begann am 20. November 1945

12 Vgl. Annette Weinke, Die Verfolgung von NS-Tätern im geteilten Deutschland. Vergangenheitsbewältigungen 1949-1969 oder: Eine deutsch-deutsche Beziehungsgeschichte im Kalten Krieg, Paderborn, München und Wien 2002.

13 Adelheid Rüter-Ehlermann, Christian F. Rüter, Fritz Bauer und Karl-Dietrich Bracher (Hg.), Justiz und NS-Verbrechen. Sammlung deutscher Strafurteile wegen nationalsozialistischer Tötungsverbrechen 1945-1999, Bde. 1-35, Amsterdam 1968-2005. 
und endete am 1. Oktober 1946 mit der Verkündung der Urteile. ${ }^{14} \mathrm{Ihm}$ folgten weitere Tribunale unter der Gerichtshoheit einzelner Nationen. Der Generalstab und das Oberkommando der Wehrmacht wurden im Hauptkriegsverbrecherprozess nicht verurteilt, aber 1948/49 fanden in Nürnberg OKW-Prozesse statt, Einzelprozesse gegen 14 Angehörige der militärischen Führungsschicht der Wehrmacht. Die alliierten Prozesse gegen Kriegsverbrecher schrieben ein neues Kapitel in der Geschichte des Völkerrechts: Erstmals wurden die Schuldigen eines Krieges und an Kriegsverbrechen Schuldige zur Verantwortung gezogen; es war dies der Versuch, Kriegsverbrechen ein für allemal zu ächten.

Die normsetzenden Nürnberger Kriegsverbrecherprozesse unterschieden Verbrechen gegen den Frieden, Verbrechen gegen die Menschlichkeit und Kriegsverbrechen, also Verstöße gegen das anerkannte Kriegsrecht. Der Nürnberger Prozess war die bis dahin nachdrücklichste politische und rechtliche Anstrengung der Staatengemeinschaft, Kriegsverbrechen durch Pönalisierung einzuschränken. Die Nürnberger Verfahren waren präzedenzlos. Zentral waren drei Aspekte: Erstens, dass die Alliierten nicht auf Gewalt, sondern auf das Recht setzten, um auf den von NSDeutschland betriebenen Zivilisationsbruch zu reagieren. Zweitens, dass die Einsicht unausweichlich geworden war, am Ende des furchtbarsten Krieges der Menschheitsgeschichte sei unerlässlich, einen internationalen Strafgerichtshof einzusetzen. Drittens, dass die Täter ohne Ansehen ihres Ranges oder ihrer Position persönlich verantwortlich sein sollten. ${ }^{15}$

Die Kritik, in Nürnberg habe »Siegerjustiz« stattgefunden und sei gegen das Gebot »nullum crimen, nulla poena sine lege« verstoßen worden, greift ins Leere. Die Alliierten argumentierten: Die deutsche Aggression habe eine einmalige Situation geschaffen; Deutschland sei zu einem »verbrecherischen Staat " geworden; die bedingungslose Kapitulation und die Übernahme der "supreme authority « durch die Alliierten, also die Besatzungsherrschaft, erlaube es, strafrechtliche Maßnahmen anzuwenden. Die juristische Zeitgeschichte ist sich weitgehend einig: »Erstmals wurden in Nürnberg höchst- und höherrangige Politiker und Militärs für ihre Taten zur Verantwortung gezogen, und kein nationales Recht und darin etwa bestehende Erlaubnisnormen vermochten sie zu schützen «. ${ }^{16}$ Dies war zukunftsweisend.

Längerfristig ergab sich aus den Nürnberger Prozessen indessen eine Konstellation, die man eine $»$ Viktimisierungsfalle« genannt hat. ${ }^{17}$ In den $1950 \mathrm{er}$ Jahren wurde

14 Vgl. Hellmuth Butterweck, Der Nürnberger Prozess. Eine Entmystifizierung, Wien 2005; Steffen Radlmaier (Hg.), Der Nürnberger Lernprozess. Von Kriegsverbrechern und Starreportern, Frankfurt a. M. 2001; Gerd R. Ueberschär (Hg.), Der Nationalsozialismus vor Gericht. Die alliierten Prozesse gegen Kriegsverbrecher und Soldaten 1943-1952, Frankfurt a.M. 1999.

15 Vgl. Gerd Hankel und Gerhard Stuby, Die Aufarbeitung von Verbrechen durch internationale Strafgerichte, in: Petra Bock und Edgar Wolfrum (Hg.), Umkämpfte Vergangenheit. Geschichtsbilder, Erinnerung und Vergangenheitspolitik im internationalen Vergleich, Göttingen 1999, S. 247-268.

16 Ibid., S. 255.

17 Thomas Kühne, Die Viktimisierungsfalle. Wehrmachtsverbrechen, Geschichtswissenschaft und symbolische Ordnung des Militärs, in: Michael Th. Greven und Oliver von Wrochem, 
nämlich in Westdeutschland die Schuldfrage externalisiert, so dass die Verbrechen und der Holocaust als Werke Hitlers bzw. der SS erschienen. Dies fundierte den Mythos von der deutschen Wehrmacht als dem Inbegriff zeitloser Soldatentugenden, und die Deutschen erschienen hierbei als passiv Duldende, als Leidende und Opfer einer skrupellosen Führung.

Als die Alliierten gleich nach Kriegsende damit begannen, deutschen Kriegs- und NS-Verbrechern den Prozess zu machen, ging es nicht allein um die Ahndung von Verletzungen des Völker-, Kriegs- und Strafrechts sowie die Verurteilung von Vergehen bisher unbekannter Art und Dimension, der »crimes against humanity« schlecht ins Deutsche übersetzt als Verbrechen gegen die Menschlichkeit. Es ging insbesondere im Hauptkriegsverbrecherprozess vor dem Internationalen Militärtribunal in Nürnberg auch um das demonstrative Verdienst, als Sieger den Besiegten trotz allem einen fairen Prozess zu machen und in Deutschland rechtsstaatliche Prinzipien wieder zur Geltung zu bringen. Tatsächlich waren 1945 manche Deutsche überrascht, dass man den Angeklagten Verteidiger zur Seite stellte, dass die ehemaligen NS-Größen vor Gericht ausführlich zu Wort kommen konnten, dass die Anklage sich die »Mühe« machte, ihnen die Vergehen, derer man sie beschuldigte, individuell nachzuweisen, und dass die Richter schließlich zu durchaus unterschiedlichen Urteilen, ja sogar zu drei Freisprüchen, gelangten.

Wie wurde über Nürnberg in den Medien berichtet? ${ }^{18}$ Zumeist wurden die Angeklagten als Spießer und biedere Familienväter beschrieben, in dem Sinne, wie es Hannah Arendt im Jahre 1944 getan hat, als sie meinte, der Familienvater sei der große Verbrecher des Jahrhunderts. ${ }^{19}$ In der Neuen Zeitung vom Dezember 1945 stand:

Wer sie so vor sich sieht, auf der hölzernen Anklagebank - Hermann Göring, der wie ein arbeitsloser Chauffeur wirkt; Seyß-Inquart, der einem durchgefallenen Studenten ähnelt; Sauckel, der wie ein diebischer Trambahnschaffner aussieht - der versucht vergebens, sich die Zwanzig als Herren Deutschlands oder der Welt vorzustellen, er kann sie nicht anders sehen als eine ertappte Bande von Straßenjungen, die eine Zeitlang in gestohlenen Anzügen umherliefen und die Passanten belästigten. ${ }^{20}$

Zum Bild der bösen Buben, die ihre Missetaten nicht zugeben wollen, passt der durchschaubare Versuch der meisten Angeklagten, ihre Macht und Bedeutung im

(Hg.), Der Krieg in der Nachkriegszeit. Der Zweite Weltkrieg in Politik und Gesellschaft der Bundesrepublik, Opladen 2000, S. 183-196.

18 Vgl. Irmela von der Lühe, »The Big 52«. Erika Manns Nürnberger Reportagen, in: Weckel und Wolfrum (Hg.), »Bestien« und »Befehlsempfänger" (wie Anm. 11), S. 25-37; Anneke de Rudder, »Ein Prozess der Männer«. Geschlechterbilder in der Berichterstattung zum Nürnberger Hauptkriegsverbrecherprozess 1945/46, in: Weckel und Wolfrum (Hg.), »Bestien « und »Befehlsempfänger« (wie Anm. 11), S. 38-65; Christine Bartlitz, Von »ungewöhnlichen Ganoven« und »erbärmlichen Kreaturen«: Täterbilder in der Berichterstattung des Berliner Rundfunks über den Nürnberger Prozess 1945/46, in: Weckel und Wolfrum (Hg.), »Bestien« und »Befehlsempfänger (wie Anm. 11), S. 66-91.

19 Hannah Arendt, Organisierte Schuld, Die Wandlung, 1, 1946, S. 333-344.

20 Cit. in de Rudder, »Ein Prozess der Männer« (wie Anm. 18), S. 51. 
Nachhinein herunterzuspielen: Plötzlich wollen sie nur kleine Männer, Befehlsempfänger, Rädchen im Getriebe gewesen sein. Für diese verlogene und deswegen völlig aussichtslose Rechtfertigungsstrategie hatten Prozessbeobachter von beiden Seiten des Atlantiks nur beißenden Spott übrig. Dies illustrieren etwa Überschriften aus den Monaten der Verteidigung: »Funk: >Ich kam immer nur bis zur Tür, aber durfte nie eintreten«", »Männer ohne Meinung«, »Streicher und Schacht rücken von sich selber ab«, »Schacht: Nicht-Pg mit goldenem Parteiabzeichen«, »Auch Herr Dönitz weiß von nichts«, "Noch ein ahnungsloser Außenminister«, "Drei ahnungslose Generalfeldmarschälle auf dem Zeugenstand «. ${ }^{21}$

Im Täterbild der Sowjetischen Besatzungszone gab es auffällige Unterschiede, die sich auf die späteren Prozesse, die in der DDR stattfanden, auswirken sollten. In den meisten Beiträgen in Radio oder Zeitung herrschte das Interpretament von den Ganoven, Hochstaplern, erbärmlichen Kreaturen vor. Göring wurde als der »fette genusssüchtige Schmarotzer am deutschen Volk« beschrieben. Das von ihm und anderen im Krieg gewonnene Vermögen wurde dem Leid und Elend des deutschen Volkes gegenüber gestellt. Man kann dies treffend auf den Begriff der »Ganovisierung « bringen. ${ }^{22}$ Welche Funktionen hatten diese Stereotype, hatten diese Täterbilder? Warum reichten millionenfacher Mord, die Abschaffung der Demokratie und die Entfesselung eines Krieges offenbar nicht aus, um die NS-Führung dauerhaft zu diskreditieren? Ganove impliziert: Betrug an der Gesellschaft; und es ist ein Begriff, in dem Kapitalismuskritik mit schwingt; Schmarotzer und Parasiten nähren sich auf Kosten einer arglosen Gesellschaft; Kriminelle nehmen sich rechtswidrig und mit Gewalt, was sie haben wollen.

Alle diese Denkfiguren enthalten die Vorstellung von Ahnungs- und Hilflosigkeit eines betrogenen Volkes, das zum Opfer wird, nicht zum Mitschuldigen. Diese medialen Strategien verfolgten bewusst oder unwillkürlich das Ziel, einen tiefen Graben zwischen dem deutschen Volk und den verantwortlichen NS-Kriegsverbrechern zu ziehen. Durch die Monopolisierung von Schuld wurde eine Gemeinsamkeit in der Mehrheitsgesellschaft gestiftet, und die Deutschen nach Hitler wurden zu einem Gemeinwesen ohne NS-Last integriert. Auch hier: Viktimisierung.

\section{Strafrechtliche Denkfiguren, Täterbilder, Entlastungsstrategien der Angeklagten}

In den Strafverfahren gegen NSG-Verbrechen standen Verbrechen zur Beurteilung an, die sich nicht nur quantitativ, sondern auch qualitativ von bisheriger Gewaltkriminalität unterschieden. War nach dem gewohnten Strafrecht ein gefährlicher Kapitalverbrecher derjenige, der mit Motiv und heimtückisch eigenhändig mordet, so sah man sich nun mit tausenden von Angeklagten konfrontiert, die ganz andere Tatmerkmale aufwiesen. Entweder hatten sie weit von den Orten massenhafter Verbre-

22 Bartlitz, Von »ungewöhnlichen Ganoven« etc. (wie Anm. 18), S. 76. 
chen entfernt furchtbare Pläne erdacht und Anweisungen gegeben, oder sie hatten ohne wirklich eigenes Interesse nur auf Anweisungen hin Menschen, die sie nicht persönlich kannten, kaltblütig verfolgt, deportiert, gefoltert und getötet. Als diese neuartigen Massenverbrechen mit dem Kriegsende weithin bekannt wurden und die Beweise nicht länger zu ignorieren waren, fragten sich viele verstört, wie solche Täter und Täterinnen wohl charakterlich beschaffen sein müssten. Man wollte wissen, wie solche Mörder aussähen und wie sie sich - ihrer Macht beraubt - vor ihren Anklägern und Richtern präsentierten. Kaum jemand mochte damals glauben, dass es sich um vergleichsweise unauffällige, gewöhnliche Männer und Frauen handelte, die ohne den Nationalsozialismus vermutlich nie einem anderen Menschen ein Haar gekrümmt hätten. Viel naheliegender und dem Entsetzen angemessener schien es, davon auszugehen, dass es teuflische oder doch zumindest abgründig schlechte Individuen gewesen sein mussten.

Durch derartige Dämonisierung erhielten die Millionen von Opfern rückwirkend immerhin Gegenspieler, die in der Tragödie ihrer gewissermaßen »würdig « schienen, wenn schon ihr Leiden und Sterben so unerträglich sinnlos gewesen war. Doch für Deutsche - und wohl nicht nur für sie - lag die Annahme einer abnormen charakterlichen oder psychischen Disposition nahe, die diesen Tätern zuzuschreiben war, die jetzt zur Verhandlung wegen Gewaltverbrechen kamen, woraus sich ergab, dass man selbst ebenso wie die nächsten Angehörigen und Freunde zu solcher Grausamkeit wie die NS-Täter niemals in der Lage war.

Allerdings wirkten die wenigsten Angeklagten in NS-Prozessen, die dem Bild der Öffentlichkeit hätten entsprechen sollen, sonderlich diabolisch, fanatisch oder wahnsinnig. Die allermeisten wegen NS-Verbrechen angeklagten Männer verzichteten darauf, (weiterhin) einem Ideal männlicher Eigenverantwortlichkeit, Entschlusskraft und soldatischer Unerschrockenheit zu genügen. Sie stilisierten sich jetzt auf einmal mit Hilfe ihrer Verteidiger als bloße »Befehlsempfänger« und »kleine Rädchen im Getriebe«, die sich im Übrigen entweder an vieles nicht mehr erinnern konnten oder angeblich nie über einen entsprechenden Durchblick verfügt hatten. Unverkennbar kehrten viele ihre kleinbürgerliche Normalität heraus, behaupteten etwa, in ihrem sonstigen Leben freundliche Gatten und Väter, gar Tierfreunde oder Blumenliebhaber gewesen zu sein. Vielfach gab es jedenfalls Widerstände, die Durchschnittlichkeit der Angeklagten anzuerkennen. Kaum jemand dachte darüber nach, welche Konsequenzen aus der Einsicht gezogen werden konnten, dass die Angeklagten sich mit dem Hinweis auf ihren Befehlsgehorsam und ihre kleinbürgerliche Existenz vor Gericht zu exkulpieren suchten.

Als Hannah Arendt in den frühen sechziger Jahren anlässlich des EichmannProzesses in Jerusalem das Diktum von der »Banalität des Bösen« prägte, schlug ihr eine Welle der Empörung entgegen. ${ }^{23}$ Viele wähnten, sie habe Eichmann verharm-

23 Hannah Arendt, Eichmann in Jerusalem. Ein Bericht von der Banalität des Bösen, München 1964, erw. Aufl., München 2004. Die Eichmann-Kontroverse ist aufgearbeitet bei Gary Smith (Hg.), Hannah Arendt Revisited. "Eichmann in Jerusalem» und die Folgen, Frankfurt a. M. 2000. 
lost oder gar die Opfer verhöhnt. Fast nie wurde wahrgenommen, dass die politische Theoretikerin, die zehn Jahre zuvor eine brilliante Analyse der totalen Herrschaft vorgelegt und dort die nationalsozialistischen Konzentrationslager das »radikal Böse« genannt hatte, selbst vor ihrer neuen Erkenntnis erschauderte. Sie sprach von einer »furchtbaren Banalität des Bösen, vor der das Wort versagt und an der das Denken scheitert«. Unabhängig davon, ob sie den gealterten, seiner Machtposition verlustig gegangenen Eichmann in ihrer Analyse unterschätzte, hat Arendt mit ihrem Buch ein Täterbild entworfen, das neuere Forschungen mit Gewinn weiterverfolgt haben. So untersucht die Täterforschung der letzten Jahrzehnte inzwischen die Wirkung von Faktoren wie Sozialisation, Karriereambitionen, Anpassungs- und Gewaltbereitschaft sowie Abstumpfung und Gruppendruck. Die Ergebnisse lassen die NS-Täter viel weniger als für grausame Verbrechen prädestinierte Dämonen denn als »ganz normale Männer « erscheinen, die sich zu ihren Taten bereit fanden, ohne sonderlich genötigt zu werden oder gar selbst bedroht zu sein. Die Forschung richtet sich nicht mehr auf die Tatsache, dass die Verbrechen geschehen konnten, sondern sie kommt zu der Erkenntnis, wie wenig erforderlich war, um Menschen unter den Verhältnissen von Nationalsozialismus und Vernichtungskrieg zu Verbrechern werden zu lassen.

Ein eigenes Thema sind die Täterbilder der angeklagten Frauen: Dass sich diese Frauen für NS-Gewaltverbrechen verantworten mussten, erschien nicht als Normalfall. Es erschien unwahrscheinlich, dass bloße Herz- und Gedankenlosigkeit ausgereicht haben könnten, sie zu Täterinnen zu machen. Sie waren nicht wie militärisch organisierte Männer in eine traditionelle Kette aus Befehl und Gehorsam eingebunden; sie konnten sich also weniger wirkungsvoll zu Befehlsempfängerinnen stilisieren. Wenn sie sich zur Erwerbsarbeit für den NS-Staat gemeldet und für seine verbrecherischen Ziele hatten einsetzen lassen, so musste - so mutmaßten viele mehr und anderes dahinter vermutet werden als bloße Suche nach Gelderwerb oder eine politische Überzeugung im Sinne des Nationalsozialismus. Je unverständlicher die Taten dieser Frauen wirkten, desto schlichter fielen die Erklärungsmuster aus, die man für sie verwandte. Die Phantasien, die das Auftreten weiblicher Angeklagter vor Gericht in der Presse und auch der Fernsehberichterstattung hervorrief, speisten sich aus sehr alten, nicht selten trivialen Vorstellungen. Das Bild von der »Bestie«, der aus Lust grausamen Frau, lag viel näher als das Stereotyp des modernen ehrgeizigen Bürokraten, der keine eigenen Wert- und Zielvorstellungen hat. Die äußerliche Erscheinung einer Angeklagten fand ausführliche Erwähnung in der Berichterstattung und wurde nach Möglichkeit fotografisch dokumentiert. Wurde eine Angeklagte attraktiv genannt, konnte ihr dies ebenso angelastet werden wie das Gegenteil. Etwa wurde die vielzitierte Schönheit der Bergen-Belsener Aufseherin Irma Grese oder die Assoziation, die Buchenwalder Kommandanten-Gattin Ilse Koch sehe aus 
»wie eine derbe Magd von der flämischen Grenze «, ${ }^{24}$ gleichermaßen wie ein Täuschungsversuch gewertet. Nicht selten projizierten Beobachter auch eine sexualisierende Wahrnehmung auf die weiblichen Angeklagten und deren mutmaßliche Motive. So hieß es 1950 in der Wochenzeitung Die Zeit über Ilse Koch, es stehe waußer Diskussion«, dass sie »über das verfügt, was man Geschlechtsmagie nennen könnte, gekoppelt mit einem grenzen- und skrupellosen Machttrieb und einer kalten Intelligenz«. ${ }^{25}$

Ich möchte festhalten: Jedem Täterbild sind Vorstellungen und Werturteile inhärent. Eine implizite Ätiologie (soll heißen: Lehre von den Ursachen) wird dem Täterbild zugrunde gelegt. Die Vorstellungskraft ist dabei nicht schrankenlos. Sie ist gebunden an das Repertoire kultureller Bilder. Oftmals wird latent ein Sinn der Verbrechen unterstellt, der nicht zwangsläufig konsistent und eindeutig sein muss. Im Gegenteil kann man sagen, dass durch die unterschiedlichen Assoziationen, die das Bild des Täters hervorruft, der Eindruck, der dadurch erzeugt wird, ambivalent und schwankend ist. Daraus ergeben sich für die Verfolgung von NS-Verbrechen folgenreiche Annahmen.

\section{Strafrechtliche Denkfiguren}

Um Täterbilder weiter zu erkunden, muss man die strafrechtlichen Denkfiguren in die Überlegungen mit einbeziehen. ${ }^{26}$ Vier solcher Denkfiguren lassen sich voneinander unterscheiden:

Erste strafrechtliche Denkfigur: Verurteilung wegen Mordes in Täterschaft

Eine erste strafrechtliche Denkfigur ist die Verurteilung wegen Mordes in Täterschaft, wozu nähere Ausführungen notwendig sind. Das Verfahren wegen Mordes hat für den Angeklagten weitreichende Folgen: Mord muss mit lebenslanger Haftstrafe geahndet werden, während bei Mordgehilfen auf Strafmilderung entschieden werden kann, die auf mindestens drei Jahre Freiheitsstrafe festzusetzen ist.

Das größte Problem bei der Festlegung des Tatbestandes ist dementsprechend die Abgrenzung zwischen Mord und Totschlag, und damit verbunden ist das weitere Problem der Teilnahmeform: Täterschaft oder Beihilfe.

Mord aus der NS-Zeit kann bekanntlich in der Bundesrepublik Deutschland uneingeschränkt verfolgt werden. Mordqualifizierende Merkmale, die auch für NS-

24 Ulrike Weckel und Edgar Wolfrum, NS-Prozesse und ihre öffentliche Resonanz aus geschlechtergeschichtlicher Perspektive, in: Weckel und Wolfrum (Hg.), »Bestien" und »Befehlsempfänger" (wie Anm. 11), S. 9-21, cit. S. 16.

25 Ibid., S. 16.

26 Dazu v.a. Freudiger, Die juristische Aufarbeitung von NS-Verbrechen (wie Anm. 7), S. 35 ff. 
Morde gelten, sind: Die Tat geschieht aus Überlegung, aus Mordlust, zur Befriedigung des Geschlechtstriebs, aus Habgier oder aus sonstigen niedrigen Beweggründen, sie wird heimtückisch begangen oder grausam oder mit gemeingefährlichen Mitteln oder um eine andere Straftat zu ermöglichen oder zu decken. Alle diese Begriffe bedürfen der inhaltlichen Konkretisierung, und sie ergibt sich aus der Rechtsprechung des Bundesgerichtshofes. Nach der BGH-Rechtsprechung sind niedrige Beweggründe solche, die als Motiv einer Tötung nach allgemeiner sittlicher Anschauung verachtenswert sind und auf tiefster Stufe stehen, z.B. Rassenhass; heimtückisch ist z.B., wenn der Täter die Arg- und Wehrlosigkeit des Opfers für seine Tat ausnutzt; und grausam ist derjenige, der seinem Opfer aus gefühlloser, unbarmherziger Gesinnung besondere Schmerzen oder Qualen zufügt. Diese Konkretisierungen wirken sich in der Rechtsprechung gegen NS-Täter aus.

Wie sieht es bei NSG-Prozessen mit täterschaftlich begangenen Morden aus, z.B. bei Massenvernichtungsverbrechen in Lagern? Ein Blick auf den Frankfurter Auschwitz-Prozess, der 1963 begann und in dem 22 Angeklagte (bei Urteilsverkündung nur noch 20) vor Gericht standen, kann dazu eine erste Antwort geben. ${ }^{27}$ Für drei Angeklagte endete der Prozess mit Freispruch. 17 wurden verurteilt, davon sechs als Mörder. Die Täterschaft wurde bei Hofmann und Kaduk ausdrücklich festgestellt. In der Urteilsbegründung geschah allerdings eine Weichenstellung: Haupttäter der Vernichtungsaktion, so das Urteil, waren Hitler, Himmler, Göring, Heydrich. »Die Tötungen der unschuldigen jüdischen Menschen haben die Haupttäter aus Rassenhass angeordnet und durchführen lassen«. Hofmann habe die Tötungen »innerlich bejaht und sie zu seiner eigenen Sache gemacht«.

Er wollte nicht nur die Taten der Haupttäter fördern, sondern im Zusammenwirken mit den NS-Machthabern und anderen SS-Führern, -Unterführern und -Männern selbst die Juden vernichten, weil er es im Interesse des NS-Staates für erforderlich hielt. Er hat somit nach der Überzeugung des Gerichts mit Täterwillen gehandelt.

27 Die Literatur ist mittlerweile angeschwollen, jüngere Arbeiten (in alphabetischer Reihenfolge): Martin Friedrich Balzer (Hg.), Der Frankfurter Auschwitz-Prozess. (1963-1965). Das schriftliche Urteil von 1966 sowie zahlreiche Zusatzmaterialien, Bonn 2004; Christian Dirks, Die Verbrechen der anderen. Auschwitz und der Auschwitz-Prozess der DDR: Das Verfahren gegen den KZ-Arzt Dr. Horst Fischer, Paderborn 2006; Fritz Bauer Institut (Hg.), Der Auschwitz-Prozeß. Tonbandmitschnitte, Protokolle, Dokumente, Berlin 2005; Bernd Naumann, Auschwitz. Bericht über die Strafsache gegen Mulka und andere vor dem Schwurgericht Frankfurt, Frankfurt a. M. 1965, Neuausgabe mit einem Nachwort von Marcel Atze und einem Text von Hannah Arendt, Berlin 2004; Conrad Taler und Werner Renz, Asche auf vereisten Wegen. Eine Chronik des Grauens. Berichte vom Auschwitz-Prozess, Köln 2003; Gerhard Werle und Thomas Wandres (Hg.), Auschwitz vor Gericht. Völkermord und bundesdeutsche Strafjustiz, mit einer Dokumentation des Auschwitz-Urteils, München 1995; Irmtrud Wojak (Hg.), „Gerichtstag halten über uns selbst ... "Geschichte und Wirkung des ersten Frankfurter Auschwitz-Prozesses, Frankfurt a. M. 2001; Irmtrud Wojak (Hg.), Auschwitz-Prozeß 4 Ks 2/63 Frankfurt am Main, Köln 2004; Irmtrud Wojak und Susanne Meinl (Hg.), Im Labyrinth der Schuld. Täter-Opfer-Ankläger, Frankfurt a. M. 2003. 
Weil er die Tat bewusst gewollt hat, habe er wie die Haupttäter aus niedrigen Beweggründen gehandelt. Auch Kaduk habe am gemeinschaftlichen Mord mitgewirkt; er habe »die Tötung der Opfer innerlich bejaht und zu seiner eigenen Sache gemacht, somit mit Täterwillen gehandelt«; niemand hatte ihm befohlen, bestimmte Häftlinge auszumustern, ihm sei ein Ermessensspielraum geblieben. ${ }^{28}$

Ein zweites Beispiel ist der zweite Treblinka-Prozess, der ab Oktober 1964 stattfand; dort standen zehn Angeklagte vor Gericht; im September 1965 wurden ein Freispruch und neun Verurteilungen ausgesprochen, davon vier lebenslang. Drei Angeklagte wurden wegen ihrer Täterschaft bei Massenmord verurteilt: Franz, Matthes und Miete. Bei der Suche nach der inneren Einstellung und nach Motiven stellte das Gericht fest, dass Judenhass, Sadismus und Geltungsbedürfnis vorhanden gewesen waren. Zu Franz heißt es in der Urteilsbegründung: »Da er im Zivil- und Militärleben überwiegend nur als Koch, also in einer untergeordneten Stellung, gearbeitet hatte, verschafften ihm derartige Demonstrationen eine tiefe Genugtuung «. ${ }^{29}$ Hier wird also die folgende Argumentationsfigur gewählt: Der soziale Status des Angeklagten war niedrig, und vor diesem Hintergrund wurde seine diagnostizierte Einstellung relevant. Er habe im »einverständlichen Eifer" wie die Haupttäter gehandelt, habe die gleiche Energie und Ausdauer wie die Taturheber selbst an den Tag gelegt, man könne kein inneres Widerstreben feststellen.

Vergleicht man Urteile aus der Zeit zwischen 1950 und 1965, so kann man Unterschiede feststellen zwischen Urteilen der frühen und der späteren Phase. In der frühen Phase war Mittäter derjenige, der an der Mordmaschine hantierte und die Ziele der Mordmaschinerie kannte (was im Lager für alle zutrifft). In der späteren Phase fällt auf: Wegen Beteiligung an den Massenmorden wird als »Mittäter« in der Regel nur noch derjenige verurteilt, dem individuell eine aktive Rolle nachgewiesen werden kann. Ein weiterer Unterschied zwischen den Jahren 1950 und 1965: der Großteil der Verantwortung für Massenmorde wurde auf die NS-Führungsclique, die Haupttäter, verlagert, wodurch alle anderen nur noch Mittäter waren. Aber in der frühen Phase bedeutete »Mittäter « noch keine Hierarchisierung der strafrechtlichen Verantwortung, während in der späteren Phase ein Bild des »Nebentäters « mit reduzierter Verantwortlichkeit gebraucht wurde.

Zentral für die strafrechtliche Schuldzumessung ist die Abgrenzung von Täterschaft und Beihilfe. Im Sinne des Strafgesetzbuches ist der Wille des Beteiligten allein entscheidend, also ist die Frage ausschlaggebend: Will er die Tat als eigene? Hat er einen Täterwillen, ein Interesse am Taterfolg? Ordnet der Täter sich nur einem fremden Willen unter, hat er demgegenüber lediglich einen Gehilfenwillen? Dabei berücksichtigten die Gerichte zudem die Umstände, nämlich die Diktatur. Bei jenen Menschen, so der Bundesgerichtshof 1962, die

Verbrechensbefehle missbilligen und ihnen widerstreben, sie aber gleichwohl aus menschlicher Schwäche ausführen, weil sie der Übermacht der Staatsautorität nicht gewachsen sind

28 Vgl. Freudiger, Die juristische Aufarbeitung von NS-Verbrechen (wie Anm. 7), S. 49.

29 Ibid., S. 53. 
oder ihr nachgeben, weil sie den Mut zum Widerstand oder die Intelligenz zur wirksamen Ausflucht nicht aufbringen, sei es auch, dass sie ihr Gewissen vorübergehend durch politische Parolen zu beschwichtigen und sich selber zu rechtfertigen suchen,

bestehe kein hinreichender Grund, sie »ausnahmslos und zwangsläufig von vornherein schon in der Beteiligungsform dem Taturheber, dem bedenkenlosen Überzeugungstäter, willigen Befehlsempfänger gleichzusetzen «. ${ }^{30}$ Die Auschwitz- und Treblinka-Urteile bezogen sich ausdrücklich auf diese Entscheidung des BGH. Demgemäß musste bei einer Verurteilung wegen Täterschaft ein großer einverständlicher Eifer nachgewiesen werden, eine Ausführung der Tat über das Anbefohlene hinaus, vor allem sichtbar in eigenmächtigen, befehlslosen Exzessen: Erst diese letzteren Merkmale der Tat waren ein Indiz für den Täterwillen.

Den Hintergrund dafür bildet die Bewertung des Befehlsnotstandes, den ein Angeklagter für sich in Anspruch nehmen kann. Die durch Befehle der Vorgesetzten nicht gedeckten Exzesse eines Untergebenen wurden in der Rechtsprechung in der Regel als kaum zu entkräftendes Indiz für dessen Täterwillen gewertet. D.h. keiner der wegen Beteiligung an Massenmorden in den Vernichtungslagern als Mittäter verurteilten Angeklagten wurde ausschließlich wegen dieser Tätigkeit verurteilt. Sondern immer kamen noch einzelne Mordtaten hinzu, die über den Vernichtungsbefehl hinausgingen. Erst die nachweisbar über das Befohlene hinausgehende Mordtat führt zu einer Verurteilung als Täter. Bei Schreibtischtätern musste auf eine andere Weise festgestellt werden, ob Befehlsnotstand vorlag. Mord in Täterschaft oder als Gehilfe hing davon ab, welche Willensrichtung bei einem Angeklagten feststellbar war. Der Grad des eigenen Interesses am Erfolg der Tat war dabei ein wesentlicher Anhaltspunkt:

Dieses Interesse braucht nicht ein materielles zu sein, es kann auch in einem persönlichen Trieb oder in einem Gefühl beruhen, wie Ehrgeiz, Eifersucht, dem Wunsch nach Rache und dgl. mehr. Das Interesse kann aber auch darin bestehen, dass eine vom Täter geteilte ideologische Anschauung den Erfolg der Tat als erstrebenswert ansieht. Wenn der Täter aus dieser Anschauung heraus sich zur Tat entschließt, handelt er aus eigenem Interesse. ${ }^{31}$

Für eine Verurteilung wegen Mordes in Täterschaft oder nur als Gehilfe war also die innerliche Identifikation und Billigung der Tat durch den Angeklagten eine wesentliche Voraussetzung.

\section{Zweite strafrechtliche Denkfigur: Strafmilderung bei Beihilfe zum Mord}

Die zweite strafrechtliche Denkfigur ist die Strafmilderung, die bei Beihilfe zum Mord gewährt wird. Dass die Beihilfe-Konstruktion in der größten Zahl der NSProzesse gegenüber der Denkfigur des Mordes in Täterschaft vorherrschte, ist das 
auffälligste Ergebnis einer quantitativen Auswertung der Urteile, die im Rahmen unseres Forschungsprojektes vorgenommen wurde. ${ }^{32}$

Man muss sich klarmachen, dass Beihilfe zum Mord aus der Zeit vor dem 5.12.1939 ebenso wie Totschlag bereits seit dem 8.5.1960 nicht mehr strafrechtlich verfolgt werden konnten, sofern die Verjährung nicht vorher unterbrochen worden war. Eine Neuregelung gab es 1969, als die Beihilfe zu NS-Mordtaten durch ein BGH-Urteil konkretisiert wurde, das den Kreis der Täter zugleich drastisch einschränkte: Wenn man »niedere Beweggründe« als ein täterbezogenes Merkmal ansieht und diese beim Gehilfen nicht nachgewiesen werden können, so entschied der BGH, dann ist Strafmilderung dringend geboten und bedeutet eine Höchststrafe von 15 Jahren. Auch die Verjährungsfrist beträgt 15 Jahre. Damit war bei dem Tatbestand »neutrale Beihilfe« rückwirkend schon zum 8.5.1960 eine Verjährung eingetreten.

Nach dem BGH-Urteil vom Mai 1969 konnte der Mordgehilfe künftig nur noch bestraft werden, wenn ihm nachzuweisen war, entweder dass sein Tatbeitrag auf eigenen »niederen Beweggründen« beruhte oder dass er zum Zeitpunkt seines Handelns die grausamen oder heimtückischen Umstände der Tatausführung kannte.

In den KZ-Prozessen wurden die Angeklagten durch die Gerichte vorwiegend unter Beihilfe zum Mord eingeordnet. Die Begründung lief so: Tötungen in Gaskammern waren Mord; die Täter waren: Hitler, Göring, Himmler, Heydrich; die Angeklagten haben dazu Beihilfe geleistet; ob die Tat als Beihilfe oder Mittäterschaft zu werten ist, ist nur anhand subjektiver Kriterien zu entscheiden: »Das bedeutet, dass Täter derjenige ist, der seinen Tatbeitrag mit dem Täterwillen (animus auctoris), Gehilfe derjenige ist, der seinen Tatbeitrag mit Gehilfenwillen (animus socii) leistet «. ${ }^{33}$ Um diese Frage zu entscheiden, beschäftigten sich die Gerichte mit der Tatherrschaft, der inneren Einstellung zum Tatgeschehen, dem eigenen Interesse sowie dem Umfang der eigenen Tatbestandsverwirklichung.

In diesem Zusammenhang wurde die Lebensführung des Angeklagten für die Tatbestandsfeststellung wichtig. So wurde in einer Urteilsbegründung argumentiert, ein Angeklagter habe sein ganzes Leben lang unbeanstandet geführt und wäre auch heute noch frei von Schuld, »wenn er nicht durch die Umstände, die letztlich außerhalb seiner Person lagen, in jene Situation hineingestellt worden wäre, aus der diese Straftaten sich schließlich entwickelten. ${ }^{34}$

Der tatsächliche Wille eines Angeklagten musste nach 20 Jahren festgestellt werden, um die Tatbeteiligung zu bewerten. Diese zu erforschen, erwies sich indessen als sehr schwierig. Häufig wurde in der Urteilsbegründung argumentiert: Unter der Herrschaft des NS habe eine beispiellose geistige Verwirrung geherrscht; in der SS seien Angeklagte der Propaganda und Beeinflussung besonders intensiv ausgesetzt gewesen; die Täter seien durch das NS-Regime missbraucht worden.

32 Siehe dazu oben, Anmerkung 6.

33 Freudiger, Die juristische Aufarbeitung von NS-Verbrechen (wie Anm. 7), S. 155.

34 Ibid., S. 156. 
Vielfach ergab sich aus diesen Argumentationen eine konstruierte Trennung zwischen der NS-Karriere und der inneren Einstellung eines Angeklagten zur Tat. Diese juristischen Überlegungen trugen jedenfalls dazu bei, dass die Denkfigur der Beihilfe zum Mord vorherrschte. Anders gesagt: die NS-Karriere eines Täters wurde nicht als Indiz für seinen Täterwillen anerkannt. Wenn ein Angeklagter auf Befehl tätig wurde und sich jeder Exzesstat im Sinne eigenhändigen Willkürmordens enthalten hatte bzw. ihm eine solche nicht nachgewiesen werden konnte, genügten für die Strafzumessung der eigene Ermessensspielraum und eine NS-Karriere nicht, um das Gericht auf seinen Täterwillen schließen zu lassen. In gewissen Fällen, so bei einem stellvertretenden Lagerkommandanten, wie im Majdanek-Urteil nachzulesen, wurde der Angeklagte unwillkürlich zu einem fremdgesteuerten Statisten der NSVernichtungsmaschinerie gemacht. Dabei war statt eines »einverständlichen Eifers« nunmehr ein »besonderer Eifer« bzw. eine »auffallende Rücksichtslosigkeit« gefordert, um eine Verurteilung als Täter zu veranlassen. Nun war eine über den Befehl hinausgehende Handlung statt des Einsatzes für den rückhaltlosen Vollzug verbrecherischer Befehle notwendig, um nicht lediglich wegen Beihilfe zum Mord verurteilt zu werden.

Strafmildernd wurde in diesen Verfahren sogar gewertet, dass die Angeklagten zwischen der Tat und ihrer Ahndung ersichtlich an einer Schuld getragen hätten. Meist wurden derartige Angeklagte als neutrale Befehlstäter ohne eigenen Handlungsspielraum klassifiziert. Sie seien lediglich ein Rädchen in einem großen, von anderen gesteuerten Räderwerk gewesen, hieß es in mancher Urteilsbegründung. Aber als Persönlichkeit sei der betreffende Angeklagte sauber und anständig geblieben, freilich der Propaganda ausgesetzt gewesen; nach dem Krieg habe er sich nichts weiter zu schulden kommen lassen.

Auffällig ist, dass es offenbar zweierlei Maß gibt, wenn die Annahme von »niederen Beweggründen« eingeführt wird. Dabei scheint der soziale Status des Angeklagten den Ausschlag zu geben. Die gesellschaftlichen Abgrenzungsgesichtspunkte zwischen Oben und Unten wurden demgemäß unwillkürlich zu Vehikeln außerrechtlicher Einflüsse auf die Rechtsprechung. Konstruktionen, die den sozialen Status zur Tatbestandsbestimmung heranziehen, zeigten sich deutlich in zahlreichen Urteilen, die gegen Akademiker gefällt wurden: Bei angeklagten Akademikern trennten die Gerichte säuberlich zwischen der Einpassung in das NS-System und der inneren Einstellung zu den Massenverbrechen. Dabei wurde unwillkürlich eine Aufspaltung von »äußerlicher Mitwirkung« und »innerlicher Anständigkeit« nahegelegt. Die meisten deutschen Gerichte wollten also nicht zur Kenntnis nehmen, dass sich viele Angehörige der Funktionseliten in erheblichem Maße mit der NS-Ideologie identifiziert hatten. Stattdessen wurden Akademiker und andere Angehörige der oberen Schichten überwiegend als Gehilfen in einem ihnen fremden Geschehen verortet. Diejenigen, die im NS-Staat Leitungsfunktionen innegehabt hatten, konnten jedenfalls im Nachkriegsdeutschland oft wieder qualifizierte Positionen einnehmen, was ihnen im Gerichtsverfahren zugute kam. Nun erschienen sie dem Gericht in Prozessen gegen NS-Täter hauptsächlich oder nur noch als achtbare Bürger und eben nicht als gemeine Verbrecher. 
Dritte strafrechtliche Denkfigur: Strafmilderung oder Straflosigkeit durch Totschlag statt Mord

Das Strafgesetzbuch legt fest: Totschlag liegt vor, wenn kein Mord qualifizierendes Merkmal festzustellen ist. Diese Bestimmung hat Auswirkungen auf das Strafmaß und wurde in einer weiteren Hinsicht folgenschwer für die Verfolgung von NSVerbrechen. Weil Totschlag wegen der gegenüber Mord geringeren Höchststrafe ab 1960 in der Strafverfolgung unter die Verjährung fiel, konnten Taten, die als Totschlag gewertet wurden, ab 1960 nicht mehr geahndet werden. Erst das Strafrechtsänderungsgesetz von 1969 dehnte die Verjährungsfrist für Totschlag auf 20 Jahre aus. Aber diese Gesetzesänderung hatte auf die Strafverfolgung der Tötungsverbrechen aus der NS-Zeit keine Wirkung mehr, da auch die 20-Jahresfrist für Totschlag im Jahr 1969 abgelaufen war.

Dies betraf vor allem die Justizverbrechen, insbesondere richterliche Todesurteile. Strafbarkeit des Richters besteht allgemein bei Rechtsbeugung und »niedrigen Beweggründen«. Für Träger der NS-Justiz galt das »Richterprivileg«, d.h. die Lehre, dass ein Richter für seine richterlichen Handlungen persönlich nicht belangt werden könne, sofern eine wichtige Bedingung erfüllt ist. ${ }^{35}$ Dieses Privileg beruht auf der Voraussetzung, dass eine unabhängige Richterschaft in einem Staat oder einer Gesellschaft besteht. Obwohl die Justiz im NS-System keineswegs unabhängig handelte, gab es eine Tendenz in der Rechtsprechung gegen Richter in der Nachkriegszeit, die Tätigkeit der Justiz im Dritten Reich gewissermaßen vom Hitler-Regime abzukoppeln, so dass unwillkürlich richterliche Unabhängigkeit während der NS-Zeit unterstellt wurde. Auch wenn die angeklagten Richter selbst Nationalsozialisten gewesen waren, wurde ihre ideologische Versticktheit in das NS-Regime in der Rechtsprechung, die sich mit ihren NS-Taten befasste, faktisch geleugnet.

Unter den Totschlag-Delikten, die vor Gerichten der Bundesrepublik verhandelt wurden, befanden sich viele Denunziationen. Für deren Strafbarkeit als vorsätzliche Tötung ist es Voraussetzung, dass der Denunzierte rechtswidrig zum Tode verurteilt wurde, und strafrechtlich ist maßgeblich, dass der Denunzierende dies wissen konnte. Gerhard Paul hat untersucht, welche Motive der Denunziation in der Urteilsfindung herausgestellt wurden, wenn ein Täter in einem NS-Prozess vor Gericht stand: In der Regel wurde die Denunziation als ein Versuch gewertet, die staatspolizeilichen Repressionsmöglichkeiten zur privaten Konfliktaustragung zu nutzen. Dabei konnten »niedrige Beweggründe« festgestellt werden. Es war indessen nicht selbstverständlich, dass unterstellt wurde, dem Denunzianten sei bewusst gewesen, dass der Denunzierte im NS-System einem rechtswidrig gefällten Todesurteil zum Opfer fallen musste.

Der Komplex der Verbrechen an den Juden wurde in den Prozessen, die wegen Totschlags-Delikten geführt wurden, grundsätzlich ausgespart. Denn bei Denunzia-

35 Vgl. Ingo Müller, Furchtbare Juristen. Die unbewältigte Vergangenheit unserer Justiz, München 1987. 
tionen und anderen Taten gegen Juden war stets der niedrige Beweggrund - Rassenhass - anzunehmen.

Vierte strafrechtliche Denkfigur: Schuldausschluss wegen »fehlendem Unrechtsbewusstein«

Bei einer Urteilsbegründung, die den Schuldausschluss wegen »fehlendem Unrechtsbewusstsein « herausstellt, steht nicht der Tatbestand oder die Teilnahmeform im Mittelpunkt, sondern bei dieser Argumentationsform bildet die Frage der strafrechtlichen Schuld des Angeklagten die zentrale Denkfigur. Dem Angeklagten, so wird argumentiert, habe bei seinem Handeln das Bewusstsein gefehlt, Unrecht zu tun. Allerdings musste man bei einer Urteilsbegründung im Sinne »fehlenden Unrechtsbewusstseins « beachten, dass die Argumentationsfigur sich überschnitt mit der ihrerseits allerdings umstrittenen »Kernbereichstheorie «, die in einem BGH-Urteil von 1952 vertreten wurde. So stellte der BGH 1952 fest: Im Bewusstsein aller zivilisierter Völker besteht ein gewisser Kernbereich des Rechts, der nach allgemeiner Rechtsüberzeugung von keinem Gesetz und keiner sonstigen obrigkeitlichen Maßnahme verletzt werden darf. ${ }^{36}$ Diese Festlegung des BGH hatte Rückwirkungen auch auf die Rechtsprechung gegen NS-Täter. Für die justitielle Bewertung der NSVerbrechen war durch das BGH-Urteil entschieden, dass die »Endlösung «, die Euthanasie und die Massentötungen sowjetischer Kriegsgefangener auch dann objektiv rechtswidrig blieben, wenn etwa dem Willen des Führers Gesetzescharakter zukam, was einen Befehlsnotstand für die Angeklagten in einem NSG-Prozess hätte begründen können.

\section{Urteilsbegründungen und strafrechtliche Denkfiguren}

Ein vorläufiges Resümee unseres Forschungsprojekts aus den bisher eingesehenen Urteilen lautet: Zu den häufigsten Milderungsgründen in Prozessen gegen NS-Täter gehörte das Argument, dass die Straftaten lange Zeit zurück lagen und das gesellschaftliche Sühnebedürfnis inzwischen stark abgenommen habe. Auch Formulierungen wie die folgenden finden sich in den Urteilsbegründungen: »Die Taten ließen als solche noch einen Rest von Menschlichkeit erkennen«. Die Argumentationsfiguren in zahlreichen Urteilsbegründungen kamen einer Bagatellisierung von NSVerbrechen nahe. $\mathrm{Zu}$ einem zentralen Argument für die Schuldmilderung entwickelte sich der Hinweis auf die exzeptionellen Verhältnisse im Dritten Reich: Kriegsgeschehen, ideologische Beeinflussung und Verhetzung sollen die Täter zu ihren Taten verleitet haben. Unter den Umständen des NS-Regimes hätten sich Menschen in 
einer »sittlich verwirrenden, mitunter ausweglosen Lage« befunden. Ein solches Versagen der sittlichen Kräfte gelte v.a. bei Menschen mit geringer Schulbildung und einfacher Denkart, die über eine ausgeprägt militärische Denkweise verfügten und somit der Propaganda besonders leicht erlegen seien. Bei Berufsoffizieren und Beamten sei demgegenüber mildernd zu berücksichtigen, dass sie »von Jugend an daran gewöhnt waren«, Befehle auszuführen und dass ihnen ein berufsbedingter Pflichteifer eigen gewesen sei.

Viele Gerichte berücksichtigten auch, dass die Angeklagten seit 1945 einen Persönlichkeitswandel gezeigt hatten. Mit dem Täter von einst hätten sie nicht mehr viel gemein. Die Denkfigur war, der Angeklagte hätte ein »ordentliches bürgerliches Leben geführt«, sich »mit Fleiß und Tüchtigkeit in den Arbeitsprozess eingeordnet« und die Familie versorgt. Dieser Argumentation lag der Gedanke zu Grunde, dass eine Wiederholung der Tat unter rechtstaatlichen Bedingungen nicht zu erwarten war. Bei der Strafzumessung spielten also der familiäre, der wirtschaftliche und der soziale Status der Angeklagten nach 1945 oftmals eine wichtige Rolle. Kurz gesagt: Je höher der soziale Status eines Angeklagten war, desto günstiger konnte für ihn die strafrechtliche Denkfigur aussehen und umso niedriger mochte das Strafmaß ausfallen. Auch Kriegsgefangenschaft, Internierung, Kriegsverletzung, Vertreibung und Familien- oder Vermögensverlust konnten in Prozessen gegen NS-Täger strafmildernd wirken.

Wiederum muss man die Frage gesondert stellen, ob Frauen vor Gericht ähnlich wie Männer behandelt wurden. Im Majdanek-Prozess, der fünf Jahre und sieben Monate (bis 1981) dauerte, gab es am Ende milde Urteile, die skandalös wirkten. Die angeklagten Männer wurden in der Verhandlung mit ihrem Namen und dem Rang, den sie im Lager Majdanek inne gehabt hatten, vorgestellt. Bei den Frauen erfuhren die Zuschauer darüber hinaus die Lagernamen, die sie von den Häftlingen erhalten hatten: »Blutige Brygida« oder »Kobyła« (die Stute). In den TVDarstellungen wurden Exzesstaten allein mit den weiblichen Angeklagten verbunden. Der Gutachter Wolfgang Scheffler äußerte sich speziell in Bezug auf die weiblichen Angeklagten vor der Kamera folgendermaßen:

Es ist eine zum Teil auf einem sehr niedrigen Niveau stehende Schicht von Frauen offensichtlich gewesen. Das ist keine Voraussetzung und das ist keine Erklärung dafür, dass einzelne davon zu Bestien geworden sind. Macht über Menschen zu haben, zumal Menschengruppen, die als verabscheuungswürdig angesehen werden, ist eine enorme Verführung. ${ }^{37}$

Die angeklagten Frauen waren zum Zeitpunkt des Majdanek-Prozesses bereits in vorgerücktem Alter; doch wurden Bilder von ihnen aus den 40er Jahren gezeigt, die die Phantasie in Gang setzen mochten: Waren derartige Frauen nicht doch von abgründiger Rätselhaftigkeit, attraktiv, von exotischer Schönheit, geltungssüchtig, mit einem Hang zu Luxus und Abenteuer? Die grausame Schöne, die Femme fatale, die

37 Vgl. Sabine Horn, »... ich fühlte mich damals als Soldat und nicht als Nazi«: Der MajdanekProzess im Fernsehen - aus geschlechtergeschichtlicher Perspektive betrachtet, in: Weckel und Wolfrum (Hg.), »Bestien« und »Befehlsempfänger« (wie Anm. 11), S. 222-249, cit. S. 237 f. 
ein katzenhaft wildes Leben führte, schien das Vorbild dieser Frauen zu sein, die sich wegen Mordes verantworten mussten. Waren sie nicht Opfer und Täterin in einer Person?

Ein kurzer Blick auf die DDR kann das bisher Gesagte ergänzen. Erst ab Anfang der 50er Jahre wurden in der DDR die NS-Strafverfahren zunehmend als politische Lehrstücke inszeniert. Erst seit dieser Zeit wurden die Prozesse zu propagandistischen Zwecken instrumentalisiert. Durch diese Veränderung erhöhten sich die Strafen erheblich und wurden zugleich neue oder andere Denkfiguren als in den unmittelbaren Nachkriegsjahren vorherrschend. Typische Bilder männlicher und weiblicher Unschuld tauchten in den Anklage- und Urteilsschriften auf, die vorher weniger präsent gewesen waren, nämlich: 1. die Entgleisung, d.h. die Einlassung, der Angeklagte könne trotz der Entgleisung unter dem NS-Regime dennoch für den (volks)demokratischen Staat gewonnen werden, da es sich um eine einmalige Entgleisung ohne Wiederholungsgefahr gehandelt habe; 2. das jugendliche Alter, wobei festgestellt wurde, der Angeklagte sei wegen des Fehlens eigener Willensbildung mit einer milderen Strafe zu belegen, da er sich lediglich einen jugendlichen Fehltritt habe zuschulden kommen lassen; oder 3. der Arbeiterstatus, was bedeutete, dass die Zugehörigkeit zur Arbeiterklasse als Garant einer apriorisch gedachten Unschuld angesehen werden könne und deshalb im strafrechtlichen Sinne eine Strafminderung rechtfertige. ${ }^{38}$

\section{Schluss \\ Erinnerungskultur, Wissenschaft und justizielle Aufarbeitung: Kongruenz oder Divergenz?}

Gerhard Paul hat kürzlich die Täter der Shoah im Spiegel der Forschung nachgezeichnet. ${ }^{39}$ Demgemäß gab es drei Phasen des Täterdiskurses der letzten sechzig Jahre: 1. Der Täterdiskurs hauptsächlich der 1950er und frühen 60er Jahre zielte auf Distanzgewinnung durch Exterritorialisierung, Kriminalisierung und Diabolisierung der Täter; die Täter wurden aus der Gesellschaft hinausinterpretiert. Anschließend und 2. wandelte sich der Täterdiskurs seit Beginn der 1960er. Bis zum Ende der 80er Jahre herrschte eine Distanzgewinnung durch Entpersonalisierung und Abstrahierung vor, wie Paul herausarbeitet; der Holocaust wurde zu einem Automatismus ohne Menschen, einer unwillkürlichen Folge auch des Siegeslaufs der Strukturgeschichte totalitärer Regimes im zwanzigsten Jahrhundert. 3. Seither sei man nun auf

38 Vgl. Insa Eschebach, Gespaltene Frauenbilder: Geschlechterdramaturgien im juristischen Diskurs ostdeutscher Gerichte, in: Weckel und Wolfrum (Hg.), »Bestien « und »Befehlsempfänger« (wie Anm. 11), S. 95-116, insbes. S. 99.

39 Gerhard Paul, Von Psychopathen, Technokraten des Terrors und »ganz gewöhnlichen« Deutschen. Die Täter der Shoah im Spiegel der Forschung, in: Gerhard Paul (Hg.), Die Täter der Shoah. Fanatische Nationalsozialisten oder ganz normale Deutsche?, Göttingen 2002, S. 1390. 
dem Weg zu den »Ordinary Men«, also hin zu einer Konkretisierung und Differenzierung der Taten, Tatmotive und Tätergruppen. Der Blick hat sich zudem auf neue Tätergruppen erweitert, etwa die Ordnungspolizei, deren Taten erst in den frühen neunziger Jahren genauer untersucht wurden. Alltags- und mentalitätsgeschichtliche Zugriffe, so Paul, dominieren im Täterdiskurs der jüngsten Zeit, und man ersetzt die Bezugnahme auf Strukturen durch die Analyse von Fallbeispielen, so dass eine dichte Beschreibung der Taten und des situativen Tatumfeldes erfolgen kann. Folge davon ist die Entschlüsselung individueller Tatmotive und auch eine Hinwendung zu Direkttätern, also nicht mehr nur stereotypisierten Täterfiguren. Dadurch wiederum sind Unterscheidungen möglich: So kann die jüngere Literatur nach Weltanschauungstätern, utilitaristisch motivierten Tätern, kriminellen Exzesstätern und traditionellen Befehlsempfängern unterscheiden.

Rückblickend lässt sich feststellen, dass sich die Sicht auf die NS-Vergangenheit zwischen 1945 und heute vielfältig gewandelt hat. Dies soll zusammenfassend anhand einiger Stichpunkte noch einmal veranschaulicht werden.

»Mit Schaudern und grenzenloser Ablehnung des Geschehens steht das deutsche Volk vor seiner eigenen Vergangenheit«, so kommentierte der alte Mann der Liberalen, Reinhold Maier, im Jahr 1965 die intensive Phase der rechtlich-politischen Auseinandersetzung mit der NS-Vergangenheit. ${ }^{40}$ Die Verjährungsdebatten des Deutschen Bundestages, begleitet von einem neu aufgelegten »Braunbuch « aus der DDR, das Anfang 1965 erschien und über mutmaßlich politisch belastete Persönlichkeiten der Bundesrepublik handelte, strahlten weit in die Öffentlichkeit aus. Sie verstärkten den Prozess der Bewusstwerdung der NS-Verbrechen in der Öffentlichkeit. Mitte der sechziger Jahre wandelte sich der landläufige und bequeme Opferdiskurs - Deutsche als Opfer Hitlers - zu einem Täterdiskurs um. Deutsche als Täter waren nun zu sehen, nicht lediglich als Opfer.

Aufklärerische Wirkungen hatten Theaterskandale. So löste Rolf Hochhuths Schauspiel Der Stellvertreter eine breite Debatte über die Duldung der NSVerbrechen durch den Vatikan aus. Golo Mann meinte dazu: Das deutsche Publikum habe sich von dem Drama ansprechen lassen wie von keinem NS-Prozess in Nürnberg oder Jerusalem und keiner noch so gründlichen historischen Studie des Instituts für Zeitgeschichte. Allemal wurde dabei der Diskurs über den Nationalsozialismus und seine Verbrechen vorangetrieben. Die öffentliche Debatte über ungesühnte Massenmorde führte zu Lernprozessen und zu einem Einstellungswandel in der Bevölkerung. Man kann im Rückblick sagen, dass in den sechziger Jahren eine neue junge Generation nunmehr die Aufarbeitung der NS-Verbrechen einforderte und dass außerdem die nationalen und internationalen Veränderungen durch die Neue Ostpolitik, die durchaus zusätzlich zur politischen eine vertiefte juristische Verantwortung für die NS-Verbrechen nahelegte, wesentlich zur Wandlung des Täterdiskurses beitrugen. ${ }^{41}$

40 Edgar Wolfrum, Geschichtspolitik in der Bundesrepublik Deutschland (wie Anm. 10), S. 237.

41 Ibid. S. $258 \mathrm{ff}$. 
Insgesamt lassen sich heute mit Blick auf den Umgang mit dem Nationalsozialismus sechs Tendenzen festhalten: 1. Eine Vielfalt der Perspektiven steht einer Beständigkeit der Kontroversen über die NS-Zeit gegenüber. 2. Das deutsche Gedächtnis ist nach wie vor auf den NS gerichtet, und er bleibt der primäre Bezugspunkt des nationalen Selbstverständnisses; die NS-Erinnerung findet nicht mehr am Rande der Gesellschaft statt, sondern sie hat mittendrin einen gewichtigen Platz erhalten; historische Schuld wird nicht mehr als Widerspruch empfunden, sondern die nationale Identität wird aus dem Holocaust und seiner Ahndung hergeleitet. 3. Das Gedächtnis wird immer stärker durchformt von den Instrumenten und Möglichkeiten der Medien; die Erinnerung an die Morde stützt sich auf die Bilder und Reportagen, die das Geschehen medial präsentabel machen. 4. Das deutsche Gedächtnis an den NS ist internationalisiert worden, und der Holocaust ist demgemäß kein exklusiv deutscher Erinnerungsort mehr; es gibt eine Art Globalisierung der NSVergangenheit, und sie dient der Mahnung der ganzen Menschheit im Sinne der Menschenrechtspolitik; dadurch wird der Holocaust des spezifisch Deutschen entkleidet, aber eine neue Dimension der Menschlichkeit wird gewonnen. 5. Das Gedächtnis löst sich gleichsam von innen auf; eine Epochenschwelle der Gedächtnisgeschichte ist überschritten worden, und wir befinden uns heute am Übergang von einem kommunikativen zu einem kulturellen Gedächtnis; dadurch werden andere Seiten der NS-Täterschaft als in früheren Jahrzehnten offenkundig. Und 6. entstehen heute im Öffentlichkeitsdiskurs ganz andere, neue Gedächtnisgeschichten, die allemal signalisieren, dass die Bundesrepublik Deutschland keine national homogene Gesellschaft ist; Zuwanderer haben ganz andere Erinnerungen und halten diese dem Erinnerungsrepertoire entgegen, das sich in den vergangenen sechzig Jahren gebildet hat. $^{42}$

Gibt es dennoch eine Kongruenz zwischen Erinnerungskultur, Wissenschaft und justizieller Aufarbeitung von NS-Verbrechen? Stimmen die Täterbilder der drei Stränge der Beschäftigung mit den NS-Taten überein? Juristen fällten oft Urteile in eigener Sache, und die moralische Exkulpation betraf vor allem den eigenen Stand, die Justiz selbst. Die juristische Ahndung war angewiesen auf das Rechtsbewusstsein der Richter, die den Gerichtshof verkörpern. Dabei mochten Justizmorde nicht mit einem negativen Täterbild in Zusammenhang gebracht werden. Die Dämonisierung der sogenannten Haupttäter - Hitler, Göring, Himmler, Heydrich - in den Argumentationen der Urteilsbegründung erfüllte jedenfalls die Funktion einer Austreibung des Nationalsozialismus. Um effektvoll exorzieren zu können, was als Teuflisches im NS geschehen war, bedurfte es einiger weniger leibhaftiger Teufel. Die Frage nach der eigenen Verantwortung, die sich viele ehemalige Richter und die meisten Angeklagten durch ihre Verteidiger hätten stellen sollen, schien somit weithin obsolet zu werden. Die Dämonisierung der NS-Größen ermöglichte einen Opfer-

42 Weitere Ausführungen: Edgar Wolfrum, Erinnerungskulturen. Thesen zur Gegenwart der NSVergangenheit, in: Stiftung Topographie des Terrors (Hg.), Gedenkstättenrundbrief, 113, 6/2003, S. 17-20. 
status selbst des Täters, der angeklagt war, und ihm wurde attestiert, dass sein Handlungsraum reduziert und seine Entscheidungsfreiheit eingeschränkt gewesen seien. Das deutsche Volk empfand sich jedenfalls als Opfergemeinschaft und mochte sich zunächst der Zukunft und dem Wiederaufbau zuwenden, was sich in zahlreichen Urteilsbegründungen abbildete.

Die Justiz erwies sich als Spiegel einer Gesellschaft, die sich über Jahrzehnte nicht zu einer konsequenten Ahndung der NS-Verbrechen durchringen konnte. Von dieser Warte aus gesehen waren die NS-Prozesse ein Vorgang, der sich nicht im unpolitischen Raum der Justiz nach abstrakten Regeln abspielte. Sondern im Nachhinein wird deutlich, wie sehr die Richter bei den Urteilsfindungen auf das gesellschaftlich vorherrschende exkulpierende Bild vom Nationalsozialismus und seinen Verbrechen rekurrierten. Dennoch war es seit Kriegsende möglich, zahlreiche NSTäter für ihre Taten zur Rechenschaft zu ziehen.

Je länger die Auseinandersetzung mit dem Nationalsozialismus andauerte, desto mehr klafften die Rechtsprechung und der öffentliche Umgang mit dem Nationalsozialismus auseinander: Die Rechtsprechung hatte sich ein Schuldmodell zurechtgelegt, das eine adäquate und konsequente Ahndung der Massenverbrechen nahezu unmöglich machte. Gesamtgesellschaftlich gesehen war indessen unerlässlich, dass eine wirksame Ahndung der NS-Taten erfolgte. Die Entwicklung war geradezu paradox: Während die Rechtsprechung die Möglichkeiten der justiziellen Ahndung von NS-Verbrechen trotz Aufhebung der Verjährung weiterhin erschwerte, wurde die Öffentlichkeit immer sensibler und forderte immer dringender, dass die NSTäter ihrer gerechten Bestrafung nicht entgehen durften. So kam es zu einer Schere zwischen dem Rechtsempfinden der Mehrheit der Bevölkerung und der Rechtsprechung in NS-Sachen. Diesen Widerspruch herauszustellen ist wichtig, weil dadurch deutlich wird, inwieweit die Justiz auf das gesellschaftliche Umfeld rückverwiesen war, in dem sie den Rechtsstaat verkörpert, was wiederum bewirkte, dass die Verfolgung der NS-Verbrechen nicht allein von den Interpretamenten der Justiz abhing.

Den Widerspruch zwischen Rechtsempfinden und Rechtsprechung kann man erforschen durch konsequente Berücksichtigung von Presseartikeln, Leserbriefen und Zuschriften an Gerichte. Das Thema in diesem Zusammenhang, dies mag deutlich geworden sein, ist die komplexe Wechselwirkung zwischen der gesellschaftlichen Geschichtskultur, der gesteuerten Vergangenheitspolitik und der justiziellen Ahndung der NS-Verbrechen. Auch im Hinblick auf andere Länder, die ihre Diktaturen zu bewältigen hatten und haben, etwa Spanien seit 1976 und jüngst die ostmitteleuropäischen Staaten, scheint mir wichtig, dass die Wechselwirkung zwischen Geschichte, Politik und Justiz bedacht wird, zumal wenn man an dem genannten Dreiecksverhältnis wahrnimmt, dass die Justiz in dieser Kette das schwächste Glied zu sein scheint. ${ }^{43}$

43 So lautet jedenfalls der Zwischenbefund laufender Arbeiten in meinem Graduiertenkolleg »Überwindung von Diktaturen und Aufbau von Zivilgesellschaften. Erfahrungen im west- und osteuropäischen Vergleich«. 